\title{
BRAZILIAN SOCIETY OF HEPATOLOGY RECOMMENDATIONS FOR THE DIAGNOSIS AND TREATMENT OF HEPATOCELLULAR CARCINOMA
}

\author{
Flair J CARRILHO'1, Angelo Alves de MATTOS², Alex F VIANEY³, Denise Cerqueira P VEZOZZO', \\ Fábio MARINHO ${ }^{4}$, Francisco J SOUTO ${ }^{5}$, Helma P COTRIM ${ }^{6}$, Henrique Sergio M COELHO7, \\ Ivonete SILVA ${ }^{8}$, José Huygens P GARCIA ${ }^{9}$, Luciana KIKUCHI ${ }^{1}$, Patricia LOFEGO' ${ }^{10}$, \\ Wellington ANDRAUS ${ }^{4}$, Edna STRAUSS ${ }^{1}$, Giovanni SILVA ${ }^{11}$, Isaac ALTIKES ${ }^{12}$, \\ Jose Eymard MEDEIROS ${ }^{13}$, Paulo L BITTENCOURT ${ }^{14}$ and Edison R PARISE ${ }^{8}$
}

\begin{abstract}
Hepatocellular carcinoma is a malignancy of global importance and is associated with a high rate of mortality. Recent advances in the diagnosis and treatment of this disease make it imperative to update the recommendations on the management of the disease. In order to draw evidence-based recommendations concerning the diagnosis and management of hepatocellular carcinoma, the Brazilian Society of Hepatology has sponsored a single-topic meeting in in João Pessoa (PB). All the invited pannelists were asked to make a systematic review of the literature and to present topics related to the risk factors for its development, methods of screening, radiological diagnosis, staging systems, curative and palliative treatments and hepatocellular carcinoma in noncirrhotic liver. After the meeting, all panelists gathered together for the discussion of the topics and the elaboration of those recommendations. The text was subsequently submitted for suggestions and approval of all members of the Brazilian Society of Hepatology through its homepage. The present paper is the final version of the reviewed manuscript containing the recommendations of the Brazilian Society of Hepatology.
\end{abstract}

HEADINGS - Hepatocelullar carcinoma. Malignant liver tumor. Screening. Diagnosis. Treatment. Carcinoma hepatocellular in noncirrhotic liver.

\section{INTRODUCTION}

The classification of levels of evidence for Brazilian Society of Hepatology recommendations for the diagnosis, staging, and treatment of hepatocellular carcinoma is based on a modification of the GRADE approach, as follows: Grade of evidence (according to the GRADE SYSTEM REFERENCE).

A - High quality - Future research is unlikely to change the presented proposition.

B - Moderate quality - Future research may have a significant impact on the presented proposition.

$\mathrm{C}$ - Low or very low quality - Future research is very likely to have a significant impact on the presented proposition.

\section{Strength of recommendation}

1 - Factors that influence the strength of recommendation include the quality of evidence, patient outcomes, and cost.

2 - Varying values and preferences, or greater uncertainty, and a weak recommendation is probably required. Recommendation is made with a lower degree of confidence, high cost, or high resource utilization.

Primary liver malignancies are the sixth most common type of cancer and the third leading cause of cancer-related death worldwide. Hepatocellular carcinoma (HCC) accounts for $85 \%-90 \%$ of primary liver neoplasms. The estimated global incidence is 500,000 $1,000,000$ new cases, leading to 600,000 deaths, per

Declared conflict of interest of all authors: non

Disclosure of funding: no funding received

${ }^{1}$ Faculdade de Medicina da Universidade de São Paulo, SP Brasil; ${ }^{2}$ Universidade Federal de Ciências da Saúde de Porto Alegre, RS, Brasil; ${ }^{3}$ Universidade Federal de Sergipe, SE, Brasil; ${ }^{4}$ Hospital Português de Beneficiência, Recife, PE, Brasil; ${ }^{5}$ Universidade Federal do Mato Grosso, MT, Brasil; ${ }^{6}$ Universidade Federal da Bahia, BA Brasil; 7 Universidade Federal do Rio de Janeiro,RJ, Brasil; ${ }^{8}$ Faculdade de Medicina da Universidade Federal de São Paulo, SP, Brasil; ${ }^{9}$ Universidade Federal do Ceará, $\mathrm{CE}$, Brasil; ${ }^{10} \mathrm{Faculdade}$ de Medicina da Universidade Federal do Espírito Santo, ES, Brasil; ${ }^{11}$ Universidade Estadual de São Paulo, SP, Brasil; ${ }^{12} \mathrm{Hospital}$ Santa Catarina e Hospital Ipiranga, SP, Brasil; ${ }^{13}$ Universidade Federal da Paraíba, PB, Brasil; ${ }^{14}$ Hospital Português, Salvador, BA, Brasil.

Correspondence: Flair Carrilho. Rua Prof. Clementino Fraga, 220, 1901 - CEP: 40170-050 - Salvador, Bahia, Brasil. E-mail: plbbr@uol.com.br 
year ${ }^{(1)}$. HCC is now the most common complication and the leading cause of death in patients with compensated liver cirrhosis $^{(2)}$. The vast majority of HCC cases are associated with cirrhosis. It is estimated that chronic hepatitis B virus (HBV) or hepatitis $\mathrm{C}$ virus ( $\mathrm{HCV}$ ) infection is implicated in more than $80 \%$ of HCC cases worldwide ${ }^{(3)}$.

From an epidemiological standpoint, HCC is characterized by wide geographic variability, with a highly heterogeneous distribution, which is probably related to etiological factors such as prevalence of $\mathrm{HBV}$ and $\mathrm{HCV}$ infection and exposure to aflatoxin B1. The majority of cases $(>80 \%)$ occur in Sub-Saharan Africa and East Asia, which are considered high-incidence areas ${ }^{(4)}$.

Recent studies conducted in Europe and the United States have demonstrated a rise in HCC-related mortality, whereas cirrhosis-related mortality rates have declined or remained stable. In the U.S., HCC is the fastest-growing cause of cancer-related death, with an $80 \%$ increase in annual incidence over the last two decades ${ }^{(4)}$.

Brazil is considered to have a low incidence of HCC. A study conducted at Hospital das Clínicas da FMUSP reported an annual incidence of $3.5 \%$ in cirrhotic patients ${ }^{(5)}$. In 2009, a nationwide survey included data from 29 centers for a total of 1,405 patients diagnosed with HCC. The median age was 59 years and 78\% were male. Liver cirrhosis was present in $98 \%$ of cases and chronic HCV infection was the most common etiology (54\%), followed by HBV (16\%) and alcoholism $(14 \%)^{(6)}$.

\section{Risk factors}

The main risk factors for $\mathrm{HCC}$ are liver cirrhosis, $\mathrm{HBV}$ and HCV infection, aflatoxin contamination of foods, alcohol abuse, diabetes, obesity, nonalcoholic fatty liver disease (NAFLD), and hereditary hemochromatosis.

Cirrhosis of any etiology is a major risk factor for the development of HCC. Among all cirrhotic patients, those with HCV cirrhosis have the highest risk of developing HCC, followed by those with hemochromatosis-related cirrhosis. Advanced age, male sex, severity of cirrhosis, and sustained inflammatory activity are predictors of $\mathrm{HCC}$ regardless of cirrhosis etiology. In cirrhosis of viral etiology, $\mathrm{HBV} / \mathrm{HCV}$ or $\mathrm{HBV} / \mathrm{HDV}$ coinfection increases the risk of $\mathrm{HCC}$, as does comorbid alcohol abuse ${ }^{(7)}$.

In patients with chronic $\mathrm{HBV}$ infection, the risk of developing $\mathrm{HCC}$ increases with hepatitis progression, $\mathrm{C}$ or B genotype (the latter is particularly associated with $\mathrm{HCC}$ development in patients under the age of 50 and those without cirrhosis), and elevated viral replication rates (HBV DNA $>10,000$ copies or 2,000 IU/mL $)^{(8-12)}$. It bears mention that even inactive carriers of $\mathrm{HBV}$ are at risk of developing $\mathrm{HCC}^{(13)}$.

In hepatitis $\mathrm{C}$, risk factors include advanced age and fibrosis as well as genotype 1 infection $^{(14,15)}$, and the synergistic effects of alcohol and diabetes are likely to be more important ${ }^{(16)}$. Sustained virologic response to therapy significantly reduces the risk of HCC, but does not eliminate it altogether, and the presence of diabetes has been associated with development of tumors even after cure of infection ${ }^{(17,18)}$.

The $\mathrm{B}$ aflatoxins are carcinogenic in a wide range of laboratory animals as well as in humans, and their presence in the diet correlates with the incidence of $\mathrm{HCC}^{(19)}$. The molecular events associated with $\mathrm{HCC}$ are related to genetic alterations and mutations (such as a p53 gene mutation) triggered by exposure to this toxin. The $249^{\text {Ser }}$ TP53 mutation has been detected in $28 \%$ of HCC samples in Brazil, which is a high prevalence rate ${ }^{(20)}$.

Abusive, prolonged alcohol intake is an established risk factor for HCC, both independently (relative risk 1.5-2.0) and in association with HCV and HBV infection ${ }^{(21-23)}$. Among alcoholics, the risk of HCC increases linearly with daily intake of $>60 \mathrm{~g} \mathrm{EtOH}$, and doubles in the presence of comorbid HCV infection $^{(21)}$.

Diabetes, overweight, and obesity are also associated with increased risk of HCC (24-26). Predictably, NAFLD particularly in the steatohepatitis phase - is a risk factor for development of liver cancer ${ }^{(27)}$.

Finally, patients with hereditary hemochromatosis are also at increased risk of developing $\mathrm{HCC}$, particularly those with cirrhosis ${ }^{(28)}$.

\section{Recommendations}

- Effective antiviral therapy, administered as early as possible, should be recommended to all patients with HBV or HCV infection (category 1A).

- Universal immunization against hepatitis B in populations at risk of developing $\mathrm{HCC}$ (1A).

- Address alcohol abuse in patients with chronic liver disease, particularly those with HCV/HBV (1B).

- Management of diabetes mellitus (2B) and obesity (1A) in patients with liver disease, and lifestyle modifications in those with NAFLD, may reduce the risk of HCC.

\section{Screening}

Some of the characteristics of HCC justify the use of screening strategies: it is a common condition, which carries high rates of morbidity and mortality, in a well-defined atrisk population (patients with chronic liver disease). Furthermore, it is amenable to detection via effective, noninvasive, low-cost diagnostic techniques and curative treatment, which can increase patient survival, is available ${ }^{(29)}$. Several studies have established the efficacy of screening for providing survival benefits, as well as the cost-effectiveness of screening strategies $^{(30-32)}$.

\section{Screening is recommended in:}

- Cirrhotic patients: Cost-effectiveness studies have shown that the incidence of $1.5 \%$ per year warrants HCC screening in this population, regardless of cirrhosis etiology. On the other hand, patients with advanced cirrhosis (Child-Pugh C) are excluded from active surveillance because they are not eligible for curative therapy, except those who are currently wait-listed for liver transplantation and could benefit from screening to upgrade priority status ${ }^{(2,7,29,33)}$. 
- Noncirrhotic patients: On the basis of incidence, adult patients of Asian or African ethnicity with active HBV infection or a family history of HCC are the groups at greatest risk of developing HCC. European and U.S. guidelines also recommend screening for patients with hepatitis $\mathrm{C}$ and bridging fibrosis ${ }^{(29,34)}$.

In this setting, transient elastography is a promising tool for stratification of patients at different HCC risk levels ${ }^{(35)}$. There is little information on the incidence of HCC in noncirrhotic patients without chronic viral infection, including those with alcoholic and nonalcoholic hepatitis, autoimmune liver disease, hemochromatosis, etc.

- Treated patients with chronic viral hepatitis: Patients with chronic HBV hepatitis who remain at risk of developing HCC due to baseline factors and those with HCV infection and advanced cirrhosis or fibrosis, despite sustained virologic response, should be offered screening $(13,17,18,36)$.

The optimal range for HCC surveillance depends on two key characteristics: rate of tumor growth to its limit of detection and rate of tumor incidence in the target population. On the basis of established knowledge about the mean tumor volume doubling time in $\mathrm{HCC}^{(29,34,37)}$, a 6-month interval between screenings is a reasonable choice. Attempts at shorter or longer intervals have not achieved superior effectiveness over the 6-month period ${ }^{(38,39)}$.

Ultrasound plays an important role in the early diagnosis of HCC, and has been adopted as the best - and only - diagnostic modality for screening purposes worldwide. The presence of a liver nodule in patients with chronic liver disease mandates further investigation to rule out or confirm early diagnosis of HCC. Ultrasound is highly recommended for this purpose, as it is a risk-free, non-radioactive, noninvasive method with good patient acceptability and moderate relative $\operatorname{cost}^{(29,34)}$. However, it is important to note that ultrasound is highly dependent on the quality of equipment and on operator expertise, which can affect the quality of screening ${ }^{(39,40)}$. Therefore, in centers that lack expertise for ultrasound examination of the liver, screening of alpha-fetoprotein (AFP) levels in blood may still be necessary. AFP levels are normal in approximately $40 \%$ of tumors, and, under optimal conditions, the addition of AFP testing increases the rate of detection of small lesions by only $6 \%-8 \%$ while substantially increasing the number of false-positive results, thus increasing the cost of screening ${ }^{(38,41)}$.

In a Brazilian cohort study, after implementation of a screening program, detection of $\mathrm{HCC}$ at a tumor diameter of $<3 \mathrm{~cm}$ increased from $14 \%$ to $32 \%$ overall and to $65 \%$ in the last period of the study, with 5-year survival rates of 50\% in patients diagnosed and treated with percutaneous ablation or liver transplantation ${ }^{(42)}$.

\section{Recommendation}

- Screening should be provided to all patients with cirrhosis of any etiology or those with hepatitis $\mathrm{C}$ and advanced fibrosis, even if already receiving antiviral therapy; and to patients with hepatitis B and a family history of HCC or those of African or Asian descent with active HBV infection (category 1A, 1B).

- These patients should undergo screening via abdominal ultrasound, performed by a skilled examiner, every 6 months (1B). Although little additional insight is provided by AFP, it is recommended that AFP testing be performed in addition to ultrasound at centers lacking the necessary imaging expertise (2C).

\section{RADIOLOGICAL DIAGNOSIS OF HEPATOCELLULAR CARCINOMA}

It is recommended that certain imaging and reporting criteria be followed for radiological diagnosis of HCC.

Computed tomography (CT) should be performed in a multislice scanner, and the following series should be imaged: noncontrast, arterial phase (20-30 sec after contrast injection), portal venous phase $(60-70 \mathrm{sec})$, and equilibrium phase $(180 \mathrm{sec})$. Contrast should be administered at a high concentration $(1.5 \mathrm{~mL} / \mathrm{Kg}$ body weight $)$ and at a rate of 4 $\mathrm{mL} / \mathrm{s}$. Magnetic resonance imaging (MRI) should ideally be performed in a high-field scanner (1.5-Tesla or greater) and the following phases obtained: T2, T1 gradient-echo (GRE) in-phase/out-of-phase; contrast-enhanced: arterial, portal venous, and equilibrium (delayed) phases.

Reports should describe the size, location, and vascularization (hypervascular/fast-flow, wash-out, compare arterial phase to equilibrium phase, which should be thoroughly evaluated) of each nodule. The radiologist should also assess macrovascular invasion of the portal or hepatic veins, distinguish tumor thrombus from bland thrombus, and evaluate extrahepatic tumor extension (metastatic lesions).

\section{Radiological diagnosis}

In recent years, a characteristic vascular pattern of HCC was identified, and noninvasive radiological modalities have progressively replaced liver biopsy for the diagnosis of HCC in a substantial number of cases, particularly in patients with cirrhosis in whom there is a risk of major complications. On dynamic CT or MRI, the typical pattern involves hypervascularization of the nodule in the arterial phase and contrast wash-out in the vascular or delayed phase ${ }^{(34)}$. Prospective studies of the discriminant ability of these parameters for noninvasive diagnosis in cirrhotic patients with tumors $0.5-2$ $\mathrm{cm}$ in diameter found $100 \%$ specificity, but low sensitivity ${ }^{(46)}$. Another study found that sequential use of two dynamic methods ${ }^{(47)}$ not only preserves this high specificity but also provides significant improvements in sensitivity for detection of tumors $1-2 \mathrm{~cm}$ in diameter (Figure 1). Therefore, it is recommended that at least two dynamic imaging methods be used to diagnose tumors $<2 \mathrm{~cm}$, although recent evidence suggests that, if the tumor exhibits the aforementioned characteristic pattern on one imaging modality, confirmation with a second method is unnecessary ${ }^{(34)}$.

Furthermore MRI and CT imaging can now be performed with diffusion techniques and so-called hepatobi- 


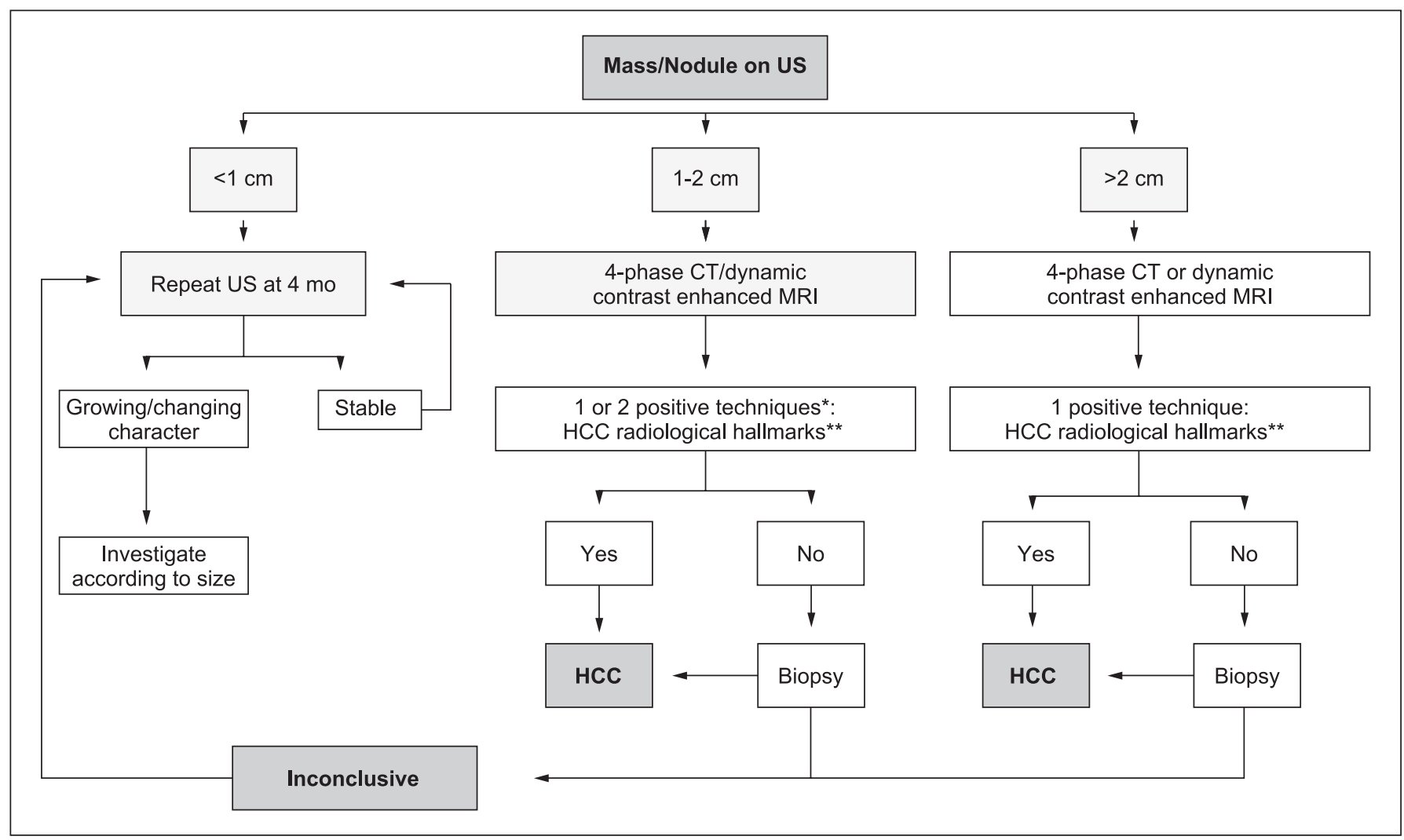

FIGURE 1. Diagnostic algorithm for hepatocellular carcinoma ${ }^{(34)}$.

liary-specific (or liver-specific) contrast media, which are characterized by hepatocyte uptake and biliary excretion. The agents employed for this purpose are gadoxetic acid and gadobenic acid (meglumine gadobenate). Recent publications have shown that liver-specific contrast agents can be useful in the differential diagnosis of small nodular lesions, to distinguish $\mathrm{HCC}$ from benign nodules

Detection and characterization of HCC, particularly in the early stages, is facilitated by use of these contrast media, because the majority of HCC lesions are hypointense on hepatobiliary-phase MRI even if the characteristic vascular pattern is not present (48-51). In one study, the adoption of liver-specific contrast changed the classification of $11.5 \%$ of patients with HCC and classified by the Barcelona Clinic Liver Cancer (BCLC) criteria as stage 0 or $\mathrm{A}^{(52)}$.

\section{Recommendations}

- Cirrhotic patients with ultrasound-detected nodules $<1 \mathrm{~cm}$ in diameter and with no diagnosis established by other imaging modalities should be followed every 3-4 (2B).

- Nodules $>1 \mathrm{~cm}$ detected on ultrasound screening in the cirrhotic liver require further investigation by $\mathrm{CT}$ or MRI (1B).

- If a liver biopsy yields inconclusive results, patients may undergo either a second biopsy or imaging-based follow-up every 3-6 months (2B).
- If imaging findings are typical for HCC, the lesion should be treated as such, regardless of liver biopsy findings (1A).

- If findings are not characteristic or the vascular profile is atypical, either a second dynamic imaging study (using another imaging modality) or a biopsy of the lesion should be performed (1B).

- Liver-specific contrast agents can be useful in the differential diagnosis of small nodular lesions, to distinguish HCC from benign nodules (2B).

\section{STAGING SYSTEMS FOR HEPATOCELLULAR CARCINOMA}

Staging systems are used to establish prognosis and to select the best candidates for optimal therapy. When designing multicenter studies to be conducted in different regions or countries, the use of staging systems helps ensure the uniformity and, consequently, the comparability of results ${ }^{(53)}$. Development of these prognostic systems takes into account the natural history of the disease and several variables related to treatment. In $\mathrm{HCC}$, a disease in which the majority of affected patients have cirrhosis, three factors are taken into consideration for assessment of prognosis: 1) Liver function, serum levels of bilirubins, and presence of ascites and portal hypertension; 2) Tumor characteristics at the time of diagnosis, such as size and number of nodules, 
presence of macrovascular invasion, and presence of metastases; and 3) the general health of the patient. In patients with solid tumors, prognosis is essentially related to tumor stage. In HCC, however, prognostication is far more complex, because the hepatic dysfunction present in the majority of cases also has a significant influence, as does the underlying clinical status and the treatment provided. On the other hand, in addition to tumor stage, the severity of hepatic dysfunction also guides the applicability and efficacy of therapy. Serum and tissue biomarkers, which are widely used in the classification of several tumor types, have yet to be validated as components of HCC staging systems and should not be used for this purpose in routine clinical practice. Studies of molecular and genetic markers are underway and may have future applicability.

Several HCC staging systems are currently available. Those most commonly used are Okuda, TNM, CLIP, CUPI, BCLC, JIS, and GRETCH ${ }^{(54-61)}$. Of these, five have been tested (BCLC, French, CLIP, CUPI, and JIS) and four have been validated (BCLC, CUPI, CLIP, and JIS). Only two (BCLC and CUPI) employ the three main prognostic factors (tumor, hepatic function, and clinical condition), and only the BCLC system determines the optimal treatment modality for each subclass. Comparative studies between these different classifications have concluded in favor of the superiority of the BCLC system ${ }^{(62,63)}$. The BCLC classification has been adopted by the European Association for the Study of the Liver (EASL), the European Organisation for Research and Treatment of Cancer (EORTC) ${ }^{(34)}$, and the American Association for the Study of Liver Diseases (AASLD) ${ }^{(29)}$.

In Brazil, only one study ${ }^{(64)}$ has compared HCC staging systems (Okuda, BCLC, CLIP, CUPI, JIS, French, Tokyo, and TNM). In this study, the BCLC and Okuda systems performed best to predict survival among Brazilian patients with HCC.

The BCLC staging system ${ }^{(55)}$ was proposed in 1999 and, unlike other classifications, is not a scoring system; it employs variables established in a variety of previous studies as independent prognostic factors. The variables taken into account are clinical condition (functional status), tumor characteristics (size and number of nodules), vascular invasion, portal hypertension, Okuda score, and Child-Pugh classification, and the system stratifies tumors into a series of risk stages $(0, A, B, C$, and D). The advantages of this system include the association of subclasses with therapeutic modality, its ability to identify early-stage tumors for treatment curative intent, its introduction of an intermediate classification (not included in other systems), and its consideration of palliative treatment and identification of end-stage disease in which supportive care alone is indicated (Figure 2).

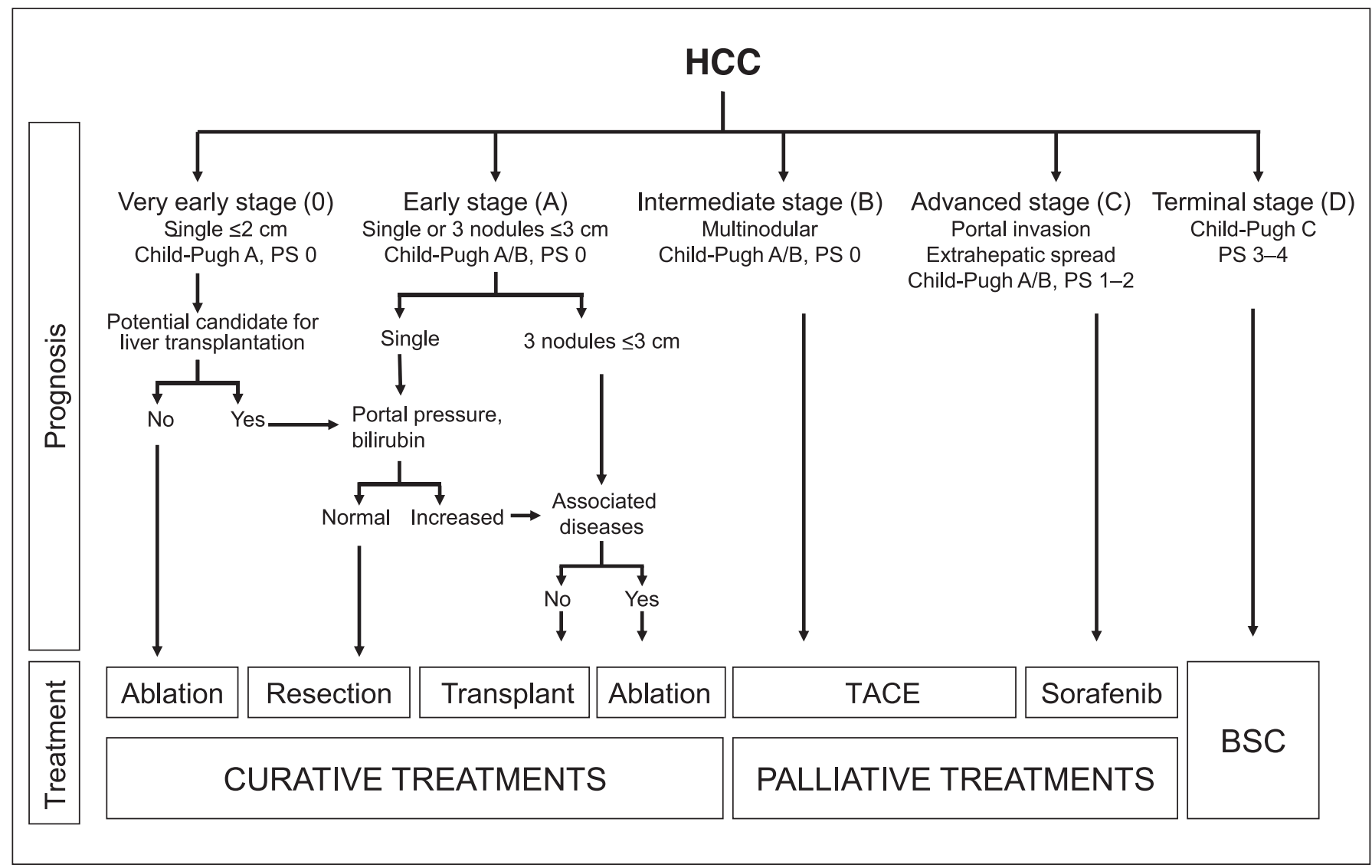

FIGURE 2. BCLC classification 


\section{Recommendation}

To adopt the Barcelona Clinic Liver Cancer (BCLC) classification as the HCC staging system of choice for use in Brazil (1B).

\section{CURATIVE AND PALLIATIVE TREATMENT}

\section{Resection}

Resection is the main treatment modality for HCC in the noncirrhotic liver, whereas liver transplantation (LTx) is considered the optimal curative treatment for hepatic cirrhosis complicated by early- or very early-stage HCC. However, the supply of organs remains insufficient to enable transplantation of all wait-listed patients. This clearly affects overall outcomes for this therapeutic modality, whether due to death on the waiting list or to patient exclusion secondary to disease progression beyond adopted criteria. As a rule, 5 -year overall survival rates after LTx for HCC are in the region of $70 \%$. However, when analysis is conducted by the intention-to-treat (ITT) principle, estimated survival is far lower. Llovet et al. ${ }^{(65)}$ highlighted this issue and demonstrated a steep decline in 2-year overall survival, from $84 \%$ to $54 \%$, after considering ITT analysis.

Surgical resection is considered a potentially curative treatment for HCC, and provides good outcomes in selected patients ${ }^{(66)}$. Technical and technological refinements and improved patient selection now produce 5-year survival rates of $50 \%-70 \%$ after resection ${ }^{(67)}$.

The optimal candidates for resection or LTx are patients with very early disease (veHCC), defined as single tumors up to $2 \mathrm{~cm}$ in size, and those with early-stage $\mathrm{HCC}(\mathrm{eHCC}$ ), with nodules meeting the Milan criteria (single tumor up to $5 \mathrm{~cm}$ in diameter or up to three tumors up to $3 \mathrm{~cm}$ in diameter). However, some case series have reported acceptable outcomes after resection in patients with more advanced $\mathrm{HCC}^{(68,69)}$.

Tumor size, number of nodules, hepatic function, and portal hypertension are predictors of prognosis after HCC resection $^{(70-72)}$. Surgical resection remains the sole treatment option for patients with veHCC and eHCC when hepatic function and clinical condition permit, largely due to the scarcity of livers for transplantation, because LTx provides superior long-term survival ${ }^{(73)}$.

Selection of the optimal therapeutic modality for HCC in patients with cirrhosis is highly challenging and requires not only adequate assessment of tumor size, number, and location, but also a thorough evaluation of hepatic functional reserve. Overall, resection is indicated in patients with compensated hepatic function (Child-Pugh A). The presence of portal hypertension, characterized by a venous pressure gradient $\geq 10 \mathrm{mmHg}$ or the presence of esophageal varices, splenomegaly, and thrombocytopenia, is one of the strongest predictors of poor survival after resection. Resection is contraindicated in Child-Pugh class C patients. However, it also bears stressing that even Child-Pugh class A patients may decompensate after larger resections ${ }^{(74)}$.

The Model for End-Stage Liver Disease (MELD) criterion, which uses creatinine, INR, and bilirubin as parameters, has been adopted in the majority of countries (including Brazil) to provide a severity-based priority criterion for LTx in wait-listed patients. However, in 2009, a research group in Bologna, Italy, published a series of 462 cirrhotic patients who had undergone hepatectomy ${ }^{(75)}$. In this case series, patients operated at a MELD score $>10$ had a 15\% rate of postoperative liver failure, regardless of the extent of resection. Other groups later reported similar results using the MELD score as a prognostic indicator of liver failure after resection.

The rate of HCC recurrence after liver resection, which approaches $70 \%$ at 5 years, remains the greatest challenge to achieving optimal survival ${ }^{(76,77)}$. Intrahepatic dissemination of primary HCC appears to account for early recurrences (occurring within 2 years of resection), whereas precancerous liver lesions are probably implicated in late recurrence.

Laparoscopic surgery is a less-invasive approach that has been increasingly used as an alternative to surgical resection for HCC treatment. It is comparable to open surgery in terms of oncologic success and survival. However, laparoscopic surgery appears to provide advantages including decreased blood loss, lower morbidity, and shorter hospital stay, although there is no high-quality evidence from prospective randomized trials to support this. The availability of laparoscopic surgery is certainly an additional argument in favor of surgical resection as a treatment modality for HCC.

\section{Recommendations}

- Resection is the main therapeutic option for HCC in the noncirrhotic liver $(1 \mathrm{~A})$.

- In the cirrhotic liver, HCC resection should be considered in patients with veHCC or eHCC and meeting the Milan criteria, with good liver function (Child-Pugh class A, normal bilirubin, and no portal hypertension) (1B).

- Use of the MELD score as an indicator of resection appears promising, but cannot yet be recommended for adoption in routine clinical practice.

\section{Liver transplantation}

It is estimated that $\mathrm{HCC}$ is the primary indication for LTx in 25\% of all cases in Europe and $40 \%$ in the United States $^{(78)}$. LTx is still the optimal treatment for HCC, as it provides radical resection (through total hepatectomy) and "cures" both cirrhosis and portal hypertension. Initially, LTx was performed indiscriminately for HCC treatment, with no established criteria, and the recurrence rate was prohibitive, in excess of 50\%. In 1996, Mazzafero et al. ${ }^{(79)}$ published a case series in the New England Journal of Medicine of transplant recipients with a single nodule up to $5 \mathrm{~cm}$ in size or up to three nodules up to $3 \mathrm{~cm}$ in size each, without evidence of vascular invasion or extrahepatic disease. Their 4-year survival rate was $74 \%$. These are now known as the Milan criteria.

In an attempt to expand the criteria for LTx and include more patients, Yao et al. ${ }^{\left({ }^{(0)}\right.}$ at the University of California, San Francisco, reported that patients with a single tumor up to $6.5 \mathrm{~cm}$ in size or up to three nodules up to $4 \mathrm{~cm}$, in size, but with a maximum total diameter of $8 \mathrm{~cm}$, had survival 
rates similar to those of patients treated within the Milan criteria. Other expanded criteria have been published in the literature, with similar results. However, a careful assessment of studies that included ITT analysis revealed a substantial reduction in post-transplantation survival with use of expanded criteria. The recommendations of the international consensus conference for LTx in HCC, led by Professor P.A. Clavien in Zurich ${ }^{(81)}$, were published in 2012. These recommendations cite the Milan criteria as the standard for inclusion of patients on a liver transplant waiting list. Patients with tumors exceeding the Milan criteria may be treated with transarterial chemoembolization (TACE) before LTx. If the tumor is found to meet Milan criteria after a few sessions of TACE (downstaging), transplantation may be indicated and provide good long-term results ${ }^{(82)}$.

\section{Recommendations}

- The Milan criteria remain the most adequate criteria for selection of HCC patients for liver transplantation.

- Patients who have been wait-listed for over 6 months should preferably undergo transarterial chemoembolization to help them continue to meet the Milan criteria.

- Patients who meet the Milan criteria after transarterial chemoembolization (downstaging) may be wait-listed for LTx and achieve good outcomes.

\section{Ablative techniques}

Ablative techniques should be considered the first-line treatment of choice for patients with early-stage $\mathrm{HCC}$ who are ineligible for surgical resection. Several techniques are effective for ablation of lesions $<3 \mathrm{~cm}$ in size. Tumor cells can be destroyed by injection of chemical substances (ethanol, acetic acid) or by temperature manipulation (laser, radiofrequency, microwaves). The most widely used ablative techniques include percutaneous ethanol injection (PEI) and radiofrequency ablation (RFA) ${ }^{(34)}$.

PEI consists of an injection of absolute alcohol through a fine needle advanced into the tumor. It is most commonly performed via the percutaneous route, under ultrasound or CT guidance. The presence of intratumoral septation and/ or a capsule limits the curative capacity of this technique, particularly in tumors larger than $2 \mathrm{~cm}$. After PEI, complete necrosis is achieved in $>90 \%$ of tumors $<2 \mathrm{~cm}, 70 \%$ of tumors $2-3 \mathrm{~cm}$ in size, and $50 \%$ of tumors $3-5 \mathrm{~cm}$ in size. The main limitation of this technique is the rate of local recurrence, which may be as high as $43 \%$ in lesions $>3 \mathrm{~cm}$. Therefore, $\mathrm{PEI}$ is indicated in patients with up to three nodules no larger than $3 \mathrm{~cm}$ in diameter each ${ }^{(83)}$.

The most common adverse events are pain, fever, and a feeling of alcohol intoxication. A decline in hepatic function is far less likely to occur after PEI than with surgical resection or chemoembolization. The mortality rate attributable to the procedure is $<1 \%$. PEI is contraindicated in cases of uncontrolled ascites or bleeding diathesis ${ }^{(83,84)}$.

In recent years, RFA has replaced PEI in some centers. It is also performed percutaneously, under ultrasound or CT guidance, by advancing a needle-shaped electrode into the tumor and applying radiofrequency energy, with the purpose of generating a thermal destruction zone that encompasses the entire tumor and a 1-cm margin around it. For tumors $2-5 \mathrm{~cm}$ in size, RFA is more effective than PEI in producing complete response, and fewer sessions are required ${ }^{(85)}$.

The primary disadvantage of RFA is its high cost and higher adverse event rate. The mortality rate attributable to the procedure ranges from zero to $0.3 \%$. RFA should be avoided if the tumor is located near the biliary tree or viscera. Furthermore, due to heat dispersion, it may be ineffective in tumors located near major blood vessels ${ }^{(8)}$.

Post-PEI or post-RFA follow-up is performed by means of dynamic imaging (CT, MRI, or contrast-enhanced ultrasound). It is recommended that follow-up imaging be performed 1 month after the last session. Complete response to treatment is defined as absence of contrast enhancement of the lesion, indicating cessation of blood supply and necrosis of the tumor ${ }^{(83)}$.

Randomized controlled trials have shown that RFA is superior to PEI in terms of achieving local disease control. Its impact on survival remains controversial. A Japanese study reported increased survival in patients treated with $\mathrm{RFA}^{(87)}$, while a European study found no significant improvement ${ }^{(88)}$. Two randomized controlled trials by Lin et al. ${ }^{(89,90)}$ reported survival advantages in favor of RFA, as compared both to PEI and percutaneous acetic acid injection (PAI), on subgroup analysis of patients with tumors $>2 \mathrm{~cm}$. The likelihood of local recurrence was significantly lower in the RFA arm (vs PEI and PAI) in four studies, whether assessed as primary or as secondary outcomes.

\section{Recommendations}

- RFA or PEI ablation is the treatment of choice for patients with BCLC stage 0/A HCC who are not eligible for surgical resection.

- RFA ablation is the preferred method for tumors $<5$ $\mathrm{cm}$, as it provides superior disease control.

- PEI is recommended in cases where RFA is not technically feasible, particularly for nodules $<3 \mathrm{~cm}$.

\section{Chemoembolization and transcatheter therapies}

TACE, drug-eluting bead chemoembolization (DABTACE), and transarterial radioembolization with yttrium-90 microspheres (TARE) are regarded as the best options for intra-arterial therapy of $\mathrm{HCC}^{(91)}$.

TACE is indicated in patients with BCLC stage B (intermediate) disease, with single tumors $>5 \mathrm{~cm}$ in diameter or multinodular tumors, as long as there is no vascular invasion or remote involvement. As a rule, it is performed preferentially in Child-Pugh class A patients, although it should not be ruled out in Child-Pugh class B patients with still-adequate hepatic functional reserve ${ }^{(92,93)}$.

Responses to TACE are heterogeneous, which is consistent with the heterogeneity of BCLC-B patients ${ }^{(94,95)}$. A meta-analysis of seven randomized controlled trials found increased survival in patients who received this procedure $(20$ months vs 16 months). Partial responses are usually observed, 
but the great merit of TACE seems to lie in its ability to slow tumor progression and vascular invasion ${ }^{(92)}$.

There is no evidence from prospective, randomized controlled trials as to how often the procedure should be performed, and no consensus on the optimal embolization agent and/or chemotherapeutic agent ${ }^{(93)}$. However, catheterization for TACE should be as selective as possible so as to minimize injury to underlying healthy tissues ${ }^{(96)}$.

The adverse effect profile of this procedure warrants attention. Adverse events are generally similar to those associated with systemic chemotherapy, and the effects of arterial obstruction may be associated with the post-embolization syndrome ${ }^{(97)}$.

A significant limitation of TACE is the high rate of tumor recurrence, which limits patient survival. Even in patients with an initial response to treatment, the cumulative likelihood of tumor recurrence is around $65 \%{ }^{(93,98)}$.

The development of drug-eluting polyvinyl chloride beads, used in the DEB-TACE technique, has decreased the incidence of side effects, as it reduces passage of the chemotherapeutic agent into the systemic circulation. In addition, as these beads can be calibrated, the degree of arterial obstruction is predictable and the procedure is made more homogeneous, with no loss of efficacy. DEB-TACE thus enables administration of high drug concentrations at the level of the tumor, with few systemic effects ${ }^{(99)}$.

The PRECISION V trial, a prospective, randomized, multicenter, phase II study that compared the efficacy of DEB-TACE versus conventional TACE, found no difference in response rate between the two procedures, but did find superior tolerance, less hepatic toxicity, and fewer systemic effects of doxorubicin in the DEB-TACE group ${ }^{(100)}$.

A study conducted by Burrel et al. ${ }^{(101)}$ highlighted the good outcomes obtained with this procedure and suggested that its indications could be expanded to create the concept of "treatment stage migration". In a recent meta-analysis, DEB-TACE proved superior to conventional treatment ${ }^{(102)}$.

However, it bears stressing that adequate assessment of treatment outcomes is difficult. Tumor necrosis, as estimated by lack of contrast uptake on dynamic imaging, appears to be the most important parameter. The modified Response Evaluation Criteria In Solid Tumors (mRECIST) evaluation has been proposed as a tool for outcome assessment. It is important to note that chemoembolization should not be repeated in patients who fail to exhibit significant necrosis after two treatment sessions; when follow-up imaging shows failure to produce significant necrosis in sites of tumor progression; and when patient assessment findings preclude safe retreatment $t^{(103,104)}$. Authors have proposed that the decision to retreat be based not only on tumor response, but also on the effects of treatment on liver function, as assessed by novel scores ${ }^{(105)}$. Treatment response may also be assessed by measuring reductions in tumor marker levels.

Chemoembolization can be combined with other therapeutic procedures ${ }^{(93,106)}$.

Recently, transarterial radioembolization with yttrium-90 microspheres (TARE) has gained favor in the literature. Pa- tients treated with this technique have shown good responses to treatment, with a mean time to tumor progression of 7.9 months and 17.2 months of survival in Child-Pugh class A patients. Adverse effects were mild, and the 30-day mortality rate was $3 \%{ }^{(107)}$. A European study ${ }^{(108)}$ reported several advantages of this technique, including the fact that it can be performed in advanced HCC ( $51 \%$ of cases were BCLC-C); in tumors both with and without vascular invasion $(31 \%$ had portal thrombosis); in patients ineligible for chemoembolization ( $47 \%$ of cases); and in those with deterioration of liver function. In addition, a multicenter study ${ }^{(109)}$ reported that TARE may translate into increased survival in in patients with advanced disease (BCLC-C). It is also interesting to note that TARE is a single-session procedure and can be performed in an outpatient setting ${ }^{(110)}$.

The role of locoregional therapy as neoadjuvant treatment to reduce dropout among patients wait-listed for LTx warrants consideration. Therefore, in centers where wait-list time exceeds 6 months, patients should be considered for chemoembolization ${ }^{(111-113)}$.

Its potential utility for downstaging of patients whose disease exceeds the Milan criteria should also be conside$\operatorname{red}^{(111,114)}$. Despite debate in the literature concerning the role of downstaging, chemoembolization could be used for this purpose. At least 3 months should be allowed to elapse between successful downstaging and $\mathrm{LTx}^{(115)}$.

\section{Recommendations}

- TACE should be performed as first-line treatment without curative intent for patients in whom surgery is not indicated, with large or multifocal HCC, no vascular invasion, and no extrahepatic involvement.

- DEB-TACE is a safer alternative, but its use is limited by its high cost.

- Both TACE and DEB-TACE could be used to prevent dropout among patients wait-listed for liver transplantation, as well as for downstaging purposes.

- TARE may be an alternative in patients with impaired liver function, portal thrombosis, and contraindications to chemoembolization.

\section{Non-curative treatment: systemic therapy}

To date, treatment strategies based on systemic chemotherapy have failed to demonstrate benefit in terms of survival and time to tumor progression ${ }^{(116)}$. A recent systematic review of the literature suggests that oxaliplatin-based chemotherapy could be beneficial in advanced HCC, although controlled trials are needed ${ }^{(117)}$.

Sorafenib is a multi-kinase inhibitor that blocks tumor cell proliferation and angiogenesis and increases the rate of tumor cell apoptosis ${ }^{(118)}$. Since 2008, with the publication of pivotal trials regarding therapy with sorafenib tosylate - to wit, the SHARP trial in the West ${ }^{(119)}$ and the Asia-Pacific study in Asia ${ }^{(120)}$ - this drug has become the only agent with scientific evidence of increased survival and prolonged time to tumor progression. Overall survival increased from 7.9 to 10.7 months in the SHARP trial and from 4.2 to 6.5 months 
in the Asia-Pacific study ${ }^{(119,120)}$. Sorafenib remains the only systemic therapy approved for HCC. A subgroup analysis of SHARP trial data suggests that improved survival occurred independently of underlying disease etiology, baseline tumor characteristics, disease stage, and prior therapy ${ }^{(121)}$.

In this context, sorafenib is indicated for patients with advanced HCC (BCLC-C). In cirrhotic patients with HCC and Child-Pugh class A liver function, treatment is well tolerated and responses have been encouraging ${ }^{(122,123)}$. However, patients in Child-Pugh class B (score $\geq 8$ ) exhibited a higher incidence of hepatic dysfunction (ascites, encephalopathy, and jaundice) and decreased survival with this treatment ${ }^{(122,123)}$.

Combination of other drugs with sorafenib, as well as its joint use with other therapeutic modalities (such as chemoembolization), have thus far failed to produce convincing results $^{(124,125)}$. A recent study suggests that combined sorafenib therapy and RFA could reduce recurrence rates and prolong mean survival in patients with intermediate-sized $\mathrm{HCC}^{(126)}$.

The most significant and most commonly reported side effects of sorafenib therapy are elevated liver enzymes, fatigue, hypertension, the hand-foot syndrome, and diarrhea ${ }^{(125)}$. Development of the hand-foot syndrome and decrease in AFP level have been associated with favorable response to treatment ${ }^{(123)}$.

\section{Recommendations}

- To date, treatment strategies based on conventional systemic chemotherapy have failed to show benefit, whether in terms of survival or in reducing time to tumor progression (level of evidence 1B, strength of recommendation $\mathrm{A}$ ).

- Sorafenib is recommended as the sole systemic therapy approved for HCC (level of evidence 1A, strength of recommendation $\mathrm{A}$ ).

- There is no robust evidence to support any benefit from drug combinations or addition of other therapeutic methods to sorafenib therapy (level of evidence $2 \mathrm{~A}$, strength of recommendation B).

\section{TREATMENT OF HEPATOCELLULAR CARCINOMA IN THE NONCIRRHOTIC LIVER}

It is estimated that, in 7\%-20\% of cases, depending on the geographic area of assessment, HCC may develop in the noncirrhotic liver (NC-HCC). HCC may arise in individuals with no evidence whatsoever of liver disease, i.e., in completely normal livers, or in the presence of inflammatory, fibrotic, or degenerative processes that have not yet reached the cirrhotic stage. NC-HCC is generally diagnosed at more advanced stages. However, when diagnosis and treatment are provided in a timely manner, patients may have a better $\operatorname{prognosis}^{(127,128)}$.

In patients with NC-HCC and no evidence of prior liver, the estimated prevalence is $10 \%-12 \%$. These cases are often associated with exposure to toxic agents such as aflatoxins, chemical agents, or radiation, or with malignant transformation of hepatic adenomas ${ }^{(127,128)}$.

Surgery is the first-line treatment option for HCC in the noncirrhotic liver, with a 5-year overall survival rate around $40 \%$ for unselected noncirrhotic patients and $64 \%-85 \%$ for selected patients or patients with a non-fibrotic liver ${ }^{(129-138)}$. The 5 -year recurrence rate is around $50 \%{ }^{(13-28)}$. For patients in whom partial liver resection may not be possible, despite the otherwise normal liver parenchyma, or because of recurrence since previous surgery, liver transplantation may be the only alternative providing a chance of cure. A systematic review published in $1999^{(138)}$ found poor 5-year survival for liver transplantation in these patients (39.4\% for the fibrolamellar type and $11.2 \%$ for conventional $\mathrm{HCC}$ ). A recently published retrospective analysis of a large cohort of patients transplanted for NC-HCC in Europe found that, in contrast to patients with $\mathrm{HCC}$ in a fibrotic or cirrhotic liver, tumor size is not an important risk factor for post-transplant survival in NC-HCC, while the presence of macrovascular invasion or hilar lymph node involvement should be considered a contraindication for transplantation. Patient selection is associated with a 5-year post-transplant survival rate of $59 \%$.

Carrilho FJ, Mattos AA, Vianey A, Vezozzo DCP, Marinho F, Souto FJ, Cotrim HP, Coelho HSM, Silva I, Garcia JHP, Kikuchi L 1, Lofego P, Andraus W, Strauss E, Silva G, Altikes I, Medeiros JE, Bittencourt PL, Parise ER. Recomendações da Sociedade Brasileira de Hepatologia para diagnóstico e tratamento do carcinoma hepatocelular. Arq Gastroenterol. 2015(Supl 1):2-14.

RESUMO - O carcinoma hepatocelular é uma neoplasia de importância global e associada a altos índices de mortalidade. Recentes avanços no diagnóstico e tratamento da doença tornaram necessárias que se atualizassem as recomendações sobre o manejo da doença. Para definir as recomendações sobre o diagnóstico e tratamento do carcinoma hepatocelular, a Sociedade Brasileira de Hepatologia organizou uma reunião monotemática em João Pessoa (PB). Todos expositores foram solicitados a fazer uma revisão sistemática da literatura e apresentar os temas relacionados a fatores de risco para o desenvolvimento de carcinoma hepatocelular, métodos para rastreamento, diagnóstico radiológico e sistemas de estadiamento da doença, tratamentos curativos e paliativos e carcinoma hepatocelular em fígado não cirrótico. Após o encontro, todos os expositores se reuniram para discussão dos tópicos e elaboração dessas recoemndações. O texto resultante foi ainda submetido a avaliação e aprovação por todos membros da Sociedade através de sua homepage. O documento atual é a versão final que contêm as recomendaçaoes da Sociedade Brasileira de Hepatologia.

DESCRITORES - Carcinoma hepatocelular. Tumores malignos do fígado. Rastreamento de tumores hepáticos. Diagnóstico e tratamento do carcinoma hepatocelular. Carcinoma hepatocelular em fígado não cirrótico. 


\section{REFERENCES}

1. Ferlay J, Shin HR, Bray F, Forman D, Mathers C, Parkin DM. Estimates of worldwide burden of cancer in 2008: GLOBOCAN 2008. Int J Cancer. 2010;127:2893-917.

2. Sangiovanni A, Prati GM, Fasani P, Ronchi G, Romeo R, Manini M e cols. The Natural History of Compensated Cirrhosis Due to Hepatites C Virus: a 17-Year Cohort Study of 214 patients. Hepatology. 2006;43: 1303-10.

3. Okuda H. Hepatocellular carcinoma development in cirrhosis. Best Practice and Research Clinical Gastroenterology. 2007;21:161-3.

4. El-Serag HB, Rudolph KL. Hepatocellular carcinoma: Epidemiology and Molecular Carcinogenesis. Gastroenterology. 2007;132:2557-76.

5. Paranagua-Vezozzo D, et al. Incidence of Hepatocellular Carcinoma in Cirrhotic Patients in São Paulo, Brasil. Hepatology. 2006;44:504.

6. Carrilho FJ, Kikuchi LOO, Branco F et al. Clinical and epidemiological aspects of hepatocellular carcinoma in Brazil. Clinics. 2010;65:1285-90.

7. Fattovich G, Stronffolini T, Zagni I, Donato F. Hepatocellular carcinoma in cirrhosis: Incidence and Risk Factors. Gastroenterology. 2004;127:35-5.

8. Chen CJ, Yang HI, Su J, Jen CL, You SL, et al. Risk of hepatocellular carcinoma across a biological gradient of serum hepatitis B virus DNA level. JAMA. 2006;295:65-73.

9. Liaw YF, Sung JJ, Chow WC, Farrell G, Lee CZ, et al. Lamivudine for patients with chronic hepatitis B and advanced liver disease. N Engl J Med. 2004;351:1521-31

10. Sung JJ, Tsoi KK, Wong VW, Li KC, Chan HL. Meta-analysis: Treatment of hepatitis B infection reduces risk of hepatocellular carcinoma. Aliment Pharmacol Ther. 2008;28:1067-77.

11. Kao JH, Chen PJ, Lai MY, Chen DS. Hepatitis B genotypes correlate with clinical outcomes in patients with chronic hepatitis B. Gastroenterology. 2000;118:554-9.

12. Chan HL, Hui AY, Wong ML, Tse AM, Hung LC, et al. Genotype C hepatitis B virus infection is associated with an increased risk of hepatocellular carcinoma. Gut. 2004;53:1494-8.

13. Chen JD, Yang HI, Iloeje UH, You SL, Lu SN, et al. Carriers of inactive hepatitis B virus are still at risk for hepatocellular carcinoma and liver-related death. Gastroenterology. 2010;138:1747-54.

14. Sun CA, Wu DM, Lin CC, Lu SN, You SL, et al. Incidence and cofactors of hepatitis $\mathrm{C}$ virus-related hepatocellular carcinoma: a prospective study of 12,008 men in Taiwan. Am J Epidemiol. 2003;157:674-82.

15. Raimondi S, Bruno S, Mondelli MU, Maisonneuve P. Hepatitis $C$ virus genotype $1 \mathrm{~b}$ as a risk factor for hepatocellular carcinoma development: a meta-analysis. J Hepatol. 2009;50:1142-54.

16. Hassan M M, Hwang L-Y, Hatten CJ, Swaim M, Li D, Abbruzzese JL, Beasley P, Patt YZ. Risk factors for hepatocellular carcinoma: Synergism of alcohol with viral hepatitis and diabetes mellitus. Hepatology. 2002, 36:1206-1213

17. Aleman S, Rahbin N, Weiland O, Davidsdottir L, Hedenstierna M, et al. A risk for hepatocellular carcinoma persists long-term after sustained virologic response in patients with hepatitis $\mathrm{C}$-associated liver cirrhosis. Clin Infect Dis. 2013;57:230-6.

18. Hung CH, Lee CM, Wang JH, Hu TH, Chen CH, Lin CY, Lu SN. Impact of diabetes mellitus on incidence of hepatocellular carcinoma in chronic hepatitis $\mathrm{C}$ patients treated with interferon-based antiviral therapy. Int J Cancer. 2011;128:2344-52.

19. Montesano R, Hainaut P, Wild CP. Hepatocellular carcinoma: from gene to public health. J Natl Cancer Inst. 1997;89:1844-51.

20. Nogueira JA, Ono-Nita SK, Nita ME et al. 249 TP53 mutation has high prevalence and is correlated with larger and poorly differentiated HCC in Brazilian patients. BMC Cancer. 2009;9:204.

21. Donato F, Tagger A, Gelatti U, Parrinello G, Boffetta P, et al. Alcohol and hepatocellular carcinoma: the effect of lifetime intake and hepatitis virus infections in men and women. Am J Epidemiol. 2002;155(4):323-31.

22. Morgan TR, Mandayam S, Jamal MM. Alcohol and hepatocellular carcinoma. Gastroenterology. 2004;127(5 Suppl 1):S87-96.
23. Pereira FE, Gonçalves CS, Zago M da P. The effect of ethanol intake on the development of hepatocellular carcinoma in HBsAg carriers. Arq Gastroenterol. 1994;31:42-6.

24. Wang P, Kang D, Cao W, Wang Y, Liu Z. Diabetes mellitus and risk of hepatocellular carcinoma: a systematic review and meta-analysis. Diabetes Metab Res Rev. 2012;28:109-22.

25. Larsson SC, Wolk A. Overweight, obesity and risk of liver cancer: a meta-analysis of cohort studies. Br J Cancer. 2007;97:1005-8.

26. Polesel J, Zucchetto A, Montella M, Dal Maso L, Crispo A, et al. The impact of obesity and diabetes mellitus on the risk of hepatocellular carcinoma. Ann Oncol. 2009;20:353-7.

27. Michelotti GA, Machado MV, Diehl AM. NAFLD, NASH and liver cancer. Nat Rev Gastroenterol Hepatol. 2013;10:656-65.

28. Fracanzani AL, Conte D, Fraquelli M, Taioli E, Mattioli M, et al. Increased cancer risk in a cohort of 230 patients with hereditary hemochromatosis in comparison to matched control patients with non-iron-related chronic liver disease. Hepatology. 2001;33:647-51.

29. Bruix J, Sherman M, et al. Management of hepatocellular carcinoma: an update. Hepatology. 2011;53:1020-2.

30. Zhang BH, Yang BH, Tang ZY. Randomized controlled trial of screening for hepatocellular carcinoma. J Cancer Res Clin Oncol. 2004;130:417-22.

31. Trevisani F, et al. Surveillance for early diagnosis of hepatocellular carcinoma: is it effective in intermediate/advanced cirrhosis? Am J Gastroenterol. 2007;102:2448-57.

32. Thompson Coon J, et al. Surveillance of cirrhosis for hepatocellular carcinoma: systematic review and economic analysis. Health Technol Assess. 2007;11:1-206.

33. Yang HI, et al. Hepatitis B e antigen and the risk of hepatocellular carcinoma. N Engl J Med. 2002;347:168-74.

34. Easl-Eortc clinical practice guidelines: management of hepatocellular carcinoma. J Hepatol. 2012;56:908-43.

35. Jung KS, et al. Risk assessment of hepatitis B virus-related hepatocellular carcinoma development using liver stiffness measurement (FibroScan). Hepatology. 2011;53:885-94.

36. Sung JJ, et al. Meta-analysis: Treatment of hepatitis B infection reduces risk of hepatocellular carcinoma. Aliment Pharmacol Ther. 2008;28: 1067-77.

37. Barbara L, et al. Natural history of small untreated hepatocellular carcinoma in cirrhosis: a multivariate analysis of prognostic factors of tumor growth rate and patient survival. Hepatology. 1992;16:132-7.

38. Trinchet JC, et al. Ultrasonographic surveillance of hepatocellular carcinoma in cirrhosis: a randomized trial comparing 3- and 6-month periodicities. Hepatology. 2011;54:1987-97.

39. Singal A, et al. Meta-analysis: surveillance with ultrasound for early-stage hepatocellular carcinoma in patients with cirrhosis. Aliment Pharmacol Ther. 2009;30:37-47.

40. Sato $\mathrm{T}$, et al. Ultrasound surveillance for early detection of hepatocellular carcinoma among patients with chronic hepatitis C. Hepatol Int. 2009;3:544-50.

41. Zhang B, Yang B. Combined alpha fetoprotein testing and ultrasonography as a screening test for primary liver cancer. J Med Screen. 1999;6:10810.

42. Paranaguá-Vezozzo DC, et al. Epidemiology of HCC in Brazil: incidence and risk factors in a ten-year cohort. Ann Hepatol. 2014;13:386-93.

43. Kojro M, Wanless IR, Alves V, Badve S, Balabaud C, Bedossa P, et al. The International Consensus Group for Hepatocellular Neoplasia. Pathologic diagnosis of early hepatocellular carcinoma: a report of the international consensus group for hepatocellular neoplasia. Hepatology. 2009;49:658-64.

44. Park YN. Update on precursor and early lesions of hepatocellular carcinomas. Arch Pathol Lab Med. 2011 ;135:704-15.

45. Di Tommaso L, Destro A, Fabbris V, Spagnuolo G, Laura Fracanzani A et al. Diagnostic accuracy of clathrin heavy chain staining in a marker panel for the diagnosis of small hepatocellular carcinoma. Hepatology. $2011 ; 53: 1549-57$. 
46. Forner A, Vilana R, Ayuso C, Bianchi L, Solé M, Ayuso JR, et al. Diagnosis of hepatic nodules $20 \mathrm{~mm}$ or smaller in cirrhosis: prospective validation of the noninvasive diagnostic criteria for hepatocellular carcinoma. Hepatology. 2008;47:97-104.

47. Yu NC, Chaudhari V, Raman SS, Lassman C, Tong MJ, Busuttil RW, et al. CT and MRI improve detection of hepatocellular carcinoma, compared with ultrasound alone, in patients with cirrhosis. Clin Gastroenterol Hepatol. 2011;9:161-7.

48. K Sano, T Ichikawa, U Motosugi, H Sou, AM Muhi, M Matsuda, et al. Imaging study of early hepatocellular carcinoma: usefulness of gadoxetic acid-enhanced MR imaging Radiology. 2011;261:834 44.

49. Motosugi T Ichikawa, H Sou, K Sano, L Tominaga, A Muhi, et al. Distinguishing hypervascular pseudolesions of the liver from hypervascular hepatocellular carcinomas with gadoxetic acid-enhanced MR imaging Radiology. 2010;256:151-8.

50. S Kogita, Y Imai, M Okada, T Kim, H Onishi, M Takamura, et al GDEOB-DTPA-enhanced magnetic resonance images of hepatocellular carcinoma: correlation with histological grading and portal blood flow Eur Radiol. 2010;20:2405-13.

51. Méndez-Sánchez N, Ridruejo E, Mattos AA, Chávez-Tapia NC, Zapata $\mathrm{R}$, et al. Asociación Latinoamericana para el Estudio del Hígado (ALEH) Guías Clínicas para el Manejo del Carcinoma Hepatocelular. Annals of Hepatology. 2014;13(Supl. 1):s4-s404.

52. Jin YJ, Nah SY, Lee JW, Lee JI, Jeong S, Lee DH, Kim YS, Cho SG, Jeon Y. Utility of adding Primovist magnetic resonance imaging to analysis of hepatocellular carcinoma by liver dynamic computed tomography. Clin Gastroenterol Hepatol. 2013;11:187-92.

53. Llovet JM, Burroughs A, Bruix J. Hepatocellular carcinoma. Lancet. 2003;362:1907-17.

54. Okuda K, Ohtsuki T, Obata H, Tomimatsu M, Okazaki N, Hasegawa H, Nakajima Y, Ohnishi K. Natural history of hepatocellular carcinoma and prognosis in relation to treatment. Study of 850 patients. Cancer. 1985;56:918-28.

55. Llovet JM, Bru C, Bruix J. Prognosis of hepatocellular carcinoma: the BCLC staging classification. Seminars in Liver Disease. 1999;19:329-38.

56. Edge SB, Byrd DR, Compton CC, Fritz AG, Greene FL, Trotti A, editors AJCC Cancer Staging Handbook. 7th ed. New York: Springer; 2010.

57. Llovet JM, Bruix J, Fuster J, Castells A, García-Valdecasas JC, Grande L, Franca A et al. Liver transplantation for treatment of small hepatocellular carcinoma: the TNM classification does not have prognostic power. Hepatology. 1998;27:1572-7.

58. The Cancer of the Liver Italian Program (CLIP) Investigators. A new prognostic system for hepatocellular carcinoma: a retrospective study of 435 patients. Hepatology. 1998;28:751-5.

59. Leung TW, Tang AM, Zee B, Lau WY, Lai PB, Leung KL, et al. Construction of the Chinese University Prognostic Index for hepatocellular carcinoma and comparison with the TNM staging system, the Okuda staging system, and the Cancer of the Liver Italian Program staging system: a study based on 926 patients. Cancer. 2002;94:1760-9.

60. Groupe d'Etude et de Traitement du Carcinome Hépatocellulaire) (Chevret S, Trinchet JC, Mathieu D, Rached AA, Beaugrand M, Chastang C. A new prognostic classification for predicting survival in patients with hepatocellular carcinoma.

61. Kitai S, Kudo M, Minami Y, Haji S, Osaki Y, Oka H, et al. Validation of a new prognostic staging system for hepatocellular carcinoma: a comparison of the biomarker-combined Japan Integrated Staging Score, the conventional Japan Integrated Staging Score and the BALAD Score. Oncology. 2008;75:S83-S90.

62. Marrero J, Fontana RJ, Barrat A, Askari F, Conjeevaram HS, Su GL, et al. Prognosis of hepatocellular carcinoma: comparison of 7 staging systems in an American cohort. Hepatology. 2005;41:707-716.

63. Cillo U, Vitale A, Grigoletto F, Farinati F, Brolese A, Zanus G, et al. Prospective validation of the Barcelona Clinic Liver Cancer staging system. J Hepatol. 2006;44:723-31.
64. Xavier FEB, 2009. Sobrevida de Pacientes com Carcinoma Hepatocelular Avaliação de Oito Sistemas de Estadiamento, [dissertação]. Ribeirão Preto: Faculdade de Medicina de Ribeirão Preto da Universidade de São Paulo

65. Llovet JM, Fuster J, Bruix J. Intention-to-treat analysis of surgical treatment for early hepatocellular carcinoma: resection versus transplantation. Hepatology. 1999;30:1434-40.

66. Taura K, Ikai I, Hatano E, Yasuchika K, Nakajima A, Tada M, et al. Influence of coexisting cirrhosis on outcomes after partial hepatic resection for hepatocellular carcinoma fulfilling the Milan criteria: an analysis of 293 patients. Surgery. 2007;142:685-94.

67. Rahbari NN, Wente MN, Schemmer P, Diener MK, Hoffmann K, Motschall E, et al. Systematic review and meta-analysis of the effect of portal triad clamping on outcome after hepatic resection. The British journal of surgery. 2008;95:424-32.

68. Chen XP, Qiu FZ, Wu ZD, Zhang BX. Hepatectomy for huge hepatocellular carcinoma in 634 cases. World journal of gastroenterology (WJG). 2006;12: 4652-5.

69. Yang T, Lin C, Zhai J, Shi S, Zhu M, Zhu N, et al. Surgical resection for advanced hepatocellular carcinoma according to Barcelona Clinic Liver Cancer (BCLC) staging. J. Cancer Res.Clinical Oncol. 2012;138:1121.

70. Zhou XD, Tang ZY, Yang BH, Lin ZY, Ma ZC, Ye SL, et al. Experience of 1000 patients who underwent hepatectomy for small hepatocellular carcinoma. Cancer. 2001;91:1479-86.

71. Ishizawa T, Hasegawa K, Aoki T, Takahashi M, Inoue Y, Sano K, et al. Neither multiple tumors nor portal hypertension are surgical contraindications for hepatocellular carcinoma. Gastroenterology. 2008;134:1908-16.

72. Ng KK, Vauthey JN, Pawlik TM, Lauwers GY, Regimbeau JM, Belghiti $\mathrm{J}$, et al. Is hepatic resection for large or multinodular hepatocellular carcinoma justified? Results from a multi-institutional database. Annals of surgical oncology. 2005;12:364-73.

73. Lin S, Hoffmann K, Schemmer P. Treatment of hepatocellular carcinoma: a systematic review. Liver cancer. 2012;1:144-58.

74. Belghiti J, Fuks D. Liver resection and transplantation in hepatocellular carcinoma. Liver cancer. 2012;1:71-82.

75. Tabrizian P, Roayaie S, Schwartz ME. Current management of hepatocellular carcinoma. World journal of gastroenterology (WJG). 2014;20:10223-37.

76. Chang WT, Kao WY, Chau GY, Su CW, Lei HJ, Wu JC, et al. Hepatic resection can provide long-term survival of patients with non-early-stage hepatocellular carcinoma: extending the indication for resection? Surgery. 2012;152:809-20.

77. Portolani N, Coniglio A, Ghidoni S, Giovanelli M, Benetti A, Tiberio GA, et al. Early and late recurrence after liver resection for hepatocellular carcinoma: prognostic and therapeutic implications. Annals of surgery. 2006;243:229-35.

78. Llovet JM, Schwartz M, Mazzaferro V. Resection and liver transplantation for hepatocellular carcinoma. Semin Liver Dis. 2005;25:181-200.

79. Mazzaferro V, et al. Liver transplantation for the treatment of small hepatocellular carcinomas in patients with cirrhosis. N Engl J Med. 1996;334:693-9.

80. Yao FY, et al. Liver transplantation for hepatocellular carcinoma: validation of the UCSF-expanded criteria based on preoperative imaging. Am J Transplant. 2007;7:2587-96.

81. Clavien PA, et al. Recommendations for liver transplantation for hepatocellular carcinoma: an international consensus conference report. Lancet Oncology. 2012;13:e11-22.

82. Yu CY, et al. Hepatocellular carcinoma downstaging in liver transplantation. Transplantation Proceedings. 2012;44:412-4.

83. Ebara M, Okabe S, Kita K, et al. Percutaneous ethanol injection for small hepatocellular carcinoma: therapeutic efficacy based on 20-year observation. J Hepatol. 2005;43:458-6.

84. Shiina S, Teratani T, Obi S, Hamamura K, Koike Y et al. Percutaneous ethanol injection therapy for liver tumors. Eur J Ultrasound. 2001;13:95106. 
85. Schwartz M, Roayaie S, Konstadoulakis M. Strategies for the management of hepatocellular carcinoma. Nat Clin Pract Oncol. 2007;4:424-32.

86. Livraghi T, Lazzaroni S, Meloni F. Radiofrequency thermal ablation of hepatocellular carcinoma. Eur J Ultrasound. 2001;13:159-66.

87. Shiina S, Teratani T, Obi S, et al. A randomized controlled trial of radiofrequency ablation with ethanol injection for small hepatocellular carcinoma. Gastroenterology. 2005;129:122-30.

88. Lencioni RA, Allgaier HP, Cioni D, et al. Small hepatocellular carcinoma in cirrhosis: randomized comparison of radio-frequency thermal ablation versus percutaneous ethanol injection. Radiology. 2003;228:35-240.

89. Lin SM, Lin CJ, Lin CC, Hsu CW, Chen YC. Radiofrequency ablation improves prognosis compared with ethanol injection for hepatocellular carcinoma $<$ or $=4 \mathrm{~cm}$. Gastroenterology. 2004;127:1714-23.

90. Lin SM, Lin CJ, Lin CC, Hsu CW, Chen YC. Randomized controlled trial comparing percutaneous radiofrequency thermal ablation, percutaneous ethanol injection, and percutaneous acetic acid injection to treat hepatocellular carcinoma of $3 \mathrm{~cm}$ or less. Gut. 2005;54:1151-6.

91. Liapi E, Geschwind JF. Intra-arterial therapies for hepatocellular carcinoma: where do we stand? Ann Surg Oncol. 2010;17:1234-46.

92. Llovet JM, Bruix J. Systematic review of randomized trials for unresectable hepatocellular carcinoma: Chemoembolization improves survival. Hepatology. 2003;37:429-42.

93. Lencioni R. Loco-regional treatment of hepatocellular carcinoma. Hepatology. 2010;52:762-73.

94. Bolondi L, Burroughs A, Dufour JF, Galle PR, Mazzaferro V, et al. Heterogeneity of patients with intermediate (BCLC B) Hepatocellular Carcinoma: proposal for a subclassification to facilitate treatment decisions. Semin Liver Dis. 2012;32:348-59.

95. Golfieri R, Renzulli M, Mosconi C, Forlani L, Giampalma E, et al. Hepatocellular carcinoma responding to superselective transarterial chemoembolization: an issue of nodule dimension? J Vasc Interv Radiol. 2013;24:509-17.

96. Golfieri R, Cappelli A, Cucchetti A, Piscaglia F, Carpenzano M, et al. Efficacy of selective transarterial chemoembolization in inducing tumor necrosis in small $(<5 \mathrm{~cm})$ hepatocellular carcinomas. Hepatology. 2011;53:1580-9.

97. Guimaraes M, Uflacker R. Locoregional therapy for hepatocellular carcinoma. Clin Liver Dis. 2011;15:395-421.

98. Woo HY, Jang JW, Choi JY, Bae SH, You CR, et al. Tumor doubling time after initial response to transarterial chemoembolization in patients with hepatocellular carcinoma. Scand J Gastroenterol. 2010;45:332-9.

99. Varela M, Real MI, Burrel M, Forner A, Sala M, et al. Chemoembolization of hepatocellular carcinoma with drug eluting beads: efficacy and doxorubicin pharmacokinetics. J Hepatol. 2007;46:474-81.

100. Lammer J, Malagari K, Vogl T, Pilleul F, Denys A, et al. Prospective randomized study of doxorubicin-eluting-bead embolization in the treatment of hepatocellular carcinoma: results of the PRECISION V study. Cardiovasc Intervent Radiol. 2010;33:41-52.

101. Burrel M, Reig M, Forner A, Barrufet M, de Lope CR, et al. Survival of patients with hepatocellular carcinoma treated by transarterial chemoembolisation (TACE) using Drug Eluting Beads. Implications for clinical practice and trial design. J Hepatol. 2012;56:1330-5.

102. Huang K, Zhou Q, Wang R, Cheng D, Ma Y. Doxorubicin-eluting beads versus conventional transarterial chemoembolization for the treatment of hepatocellular carcinoma. J Gastroenterol Hepatol. 2014;29:920-5.

103. Bruix J, Reig M, Rimola J, Forner A, Burrel M, et al. Clinical decision making and research in hepatocellular carcinoma: pivotal role of imaging techniques. Hepatology. 2011;54:2238-44.

104. Raoul JL, Sangro B, Forner A, Mazzaferro V, Piscaglia F et al. Evolving strategies for the management of intermediate-stage hepatocellular carcinoma: available evidence and expert opinion on the use of transarterial chemoembolization. Cancer Treat Rev. 2011;37:212-20.
105. Sieghart W, Hucke F, Pinter M, Graziadei I, Vogel W, et al. The ART of decision making: retreatment with transarterial chemoembolization in patients with hepatocellular carcinoma. Hepatology. 2013;57:2261-73

106. Lencioni R, Crocetti L, Petruzzi P, Bozzi E, Della Pina C, et al. Doxorubicin-eluting beadenhanced radiofrequency ablation of hepatocellular carcinoma: a pilot clinical study. J Hepatol. 2008;49:217-22.

107. Salem R, Lewandowski RJ, Mulcahy MF, Riaz A, Ryu RK, et al. Radioembolization for hepatocellular carcinoma using Yttrium-90 microspheres: a comprehensive report of long-term outcomes. Gastroenterology. 2010;138:52-64.

108. Hilgard P, Hamami M, Fouly AE, Scherag A, Müller S, et al. Radioembolization with yttrium-90 glass microspheres in hepatocellular carcinoma: European experience on safety and long-term survival. Hepatology. 2010;52:1741-9.

109. Sangro B, Carpanese L, Cianni R, Golfieri R, Gasparini D, et al. Survival after yttrium-90 resin microsphere radioembolization of hepatocellular carcinoma across Barcelona clinic liver cancer stages: a European evaluation. Hepatology. 2011;54:868-78.

110. Salem R, Lewandowski RJ.Chemoembolization and radioembolization for hepatocellular carcinoma. Clin Gastroenterol Hepatol. 2013;11:60411.

111. Forner A, Ayuso C, Isabel RM, Sastre J, Robles R, et al. Diagnosis and treatment of hepatocellular carcinoma. 2009;132:272-87.

112. Llovet JM, Bruix J. Novel advancements in the management of hepatocellular carcinoma in 2008. J Hepatol. 2008;48:S20-S37.

113. Majno P, Lencioni R, Mornex F, Girard N, Poon RT, et al. Is the treatment of hepatocellular carcinoma on the waiting list necessary? Liver Transpl. 2011;17:S98-108.

114. Silva MF, Sherman M. Criteria for liver transplantation for HCC: what should the limits be? J Hepatol. 2011;55:1137-47

115. Yao FY, Breitenstein S, Broelsch CE, Dufour JF, Sherman M, et al. Does a patient qualify for liver transplantation after the down-staging of hepatocellular carcinoma? Liver Transpl. 2011;17:S109-S116.

116. Peck-Radosavljevic M. Drug therapy for advanced-stage liver cancer. Liver Cancer. 2014;3:125-31.

117. Petrelli F, Coinu A, Borgonovo K, Cabiddu M, Ghilardi M, Lonati V, Barni S. Oxaliplatin-based chemotherapy: a new option in advanced hepatocellular carcinoma. a systematic review and pooled analysis. Clin Oncol (R Coll Radiol). 2014;26:488-96.

118. Chang YS, Adnane J, Trail PA, et al. Sorafenib inhibitis tumor growth and vascularization end induces tumor apoptosis and hypoxia in RCC xenograph models. Cancer Chemotherapy Pharmacol. 2007;59:561-74.

119. Josep M. Llovet, Sergio Ricci, Vincenzo Mazzaferro, Philip Hilgard, Edward Gane, et al. Sorafenib in advanced hepatocellular carcinoma. N Engl J Med. 2008;359:378-90.

120. Cheng AL, Kang YK, Chen Z, Tsao CJ, Qin S, et al. Efficacy and safety of sorafenib in patients in the Asia-Pacific region with advanced hepatocellular carcinoma: a phase III randomised, double-blind, placebo-controlled trial. Lancet Oncol. 2009;10:25-34

121. Bruix J, Raoul JL, Sherman M, Mazzaferro V, Bolondi L, Craxi A, Galle PR, Santoro A, Beaugrand M, Sangiovanni A, Porta C, Gerken G, Marrero JA, Nadel A, Shan M, Moscovici M, Voliotis D, Llovet JM. Efficacy and safety of sorafenib in patients with advanced hepatocellular carcinoma: subanalyses of a phase III trial. J Hepatol. 2012;57:821-9.

122. Shen A, Tang C, Wang Y, Chen Y, Yan X, Zhang C, Liu R, Wei X, Zhu Y, Zhang H, Wu Z. A systematic review of sorafenib in Child-Pugh A patients with unresectable hepatocellular carcinoma. J Clin Gastroenterol. 2013;47:871-80.

123. Ogasawara S, Chiba T, Ooka Y, Kanogawa N, Saito T, Motoyama T, Suzuki E, Tawada A, Kanai F, Yokosuka O. Sorafenib treatment in ChildPugh A and B patients with advanced hepatocellular carcinoma: safety, efficacy and prognostic factors. Invest New Drugs. 2015;33:729-39. 
124. Zhu AX, Rosmorduc O, Evans J, Ross P, Santoro A, Carrilho FJ, et al: Search: a phase III, randomized, double blind, placebo-controlled trial of sorafenib plus erlotinib in patients with hepatocellular carcinoma (HCC) Ann Oncol. 2012;23(Suppl 9):A917.

125. Abdel-Rahman O, Fouad M. Sorafenib-based combination as a first line treatment for advanced hepatocellular carcinoma: a systematic review of the literature. Crit Rev Oncol Hematol. 2014;91:1-8.

126. Kan X, Jing Y, Wan QY, Pan JC, Han M, Yang Y, Zhu M, Wang Q, Liu $\mathrm{KH}$. Sorafenib combined with percutaneous radiofrequency ablation for the treatment of medium-sized hepatocellular carcinoma. Eur Rev Med Pharmacol Sci. 2015;19:247-55.

127. Trevisani F, Frigerio M, Santi V, Grignaschi A, Bernardi M. Hepatocellular carcinoma in non-cirrhotic liver: a reappraisal. Dig Liver Dis. 2010;42:341-7.

128. Alkofer B, Lepennec V, Chiche L. Hepatocellular cancer in the non-cirrhotic liver. J Visc Surg. 2011;148:3-11.

129. Ringe B, Pichlmayr R, Wittekind C, Tusch G. Surgical treatment of hepatocellular carcinoma: experience with liver resection and transplantation in 198 patients. World J Surg. 1991;15:270-85.

130. Grazi GL, Cescon M, Ravaioli M, et al. Liver resection for hepatocellular carcinoma in cirrhotics and noncirrhotics. Evaluation of clinicopathologic features and comparison of risk factors for long-term survival and tumour recurrence in a single centre. Aliment Pharmacol Ther. 2003;17:119-29.
131. Chang CH, Chau GY, Lui WY, et al. Long-term results of hepatic resection for hepatocellular carcinoma originating from the noncirrhotic liver Arch Surg. 2004;139:320-5.

132. Nagasue N, Ono T, Yamanoi A, et al. Prognostic factor and survival after hepatic resection for hepatocellular carcinoma without cirrhosis. Br J Surg. 2001;88:515-22.

133. Dupont-Bierre E, Compagnon P, Raoul JL, et al. Resection of hepatocellular carcinoma in noncirrhotic liver: analysis of risk factors for survival. J Am Coll Surg. 2005;201:663-70.

134. Laurent C, Blanc JF, Nobili S, et al. Prognostic factors and longterm survival after hepatic resection for hepatocellular carcinoma originating from noncirrhotic liver. J Am Coll Surg. 2005;201:656-62.

135. Lang H, Sotiropoulos GC, Brokalaki EI, et al. Survival and recurrence rates after resection for hepatocellular carcinoma in noncirrhotic livers. J Am Coll Surg. 2007;205:27-36.

136. Rayya F, Harms J, Bartels M, et al. Results of resection and transplantation for hepatocellular carcinoma in cirrhosis and noncirrhosis. Transplant Proc. 2008;40:933-5.

137. Wörns MA, Bosslet T, Victor A, Koch S, Hoppe-Lotichius M, et al. Prognostic factors and outcomes of patients with hepatocellular carcinoma in non-cirrhotic liver.Scand J Gastroenterol. 2012;47:718-28.

138. Houben KW, McCall JL. Liver transplantation for hepatocellular carcinoma in patients without underlying liver disease: a systematic review. Liver Transplant Surg. 1999;5:91-5 